\title{
C-E Translation of Public Signs in Wuliangye Ten-Mile Liquor City, Yibin
}

\author{
Hongying Li \\ School of Economics, Sichuan University of Science \& Engineering, Zigong, China \\ Email: lihongying314@163.com
}

How to cite this paper: Li, H.Y. (2018) C-E Translation of Public Signs in Wuliangye Ten-Mile Liquor City, Yibin. Open Access Library Journal, 5: e4579.

https://doi.org/10.4236/oalib.1104579

Received: April 7, 2018

Accepted: May 11, 2018

Published: May 14, 2018

Copyright (c) 2018 by author and Open Access Library Inc.

This work is licensed under the Creative Commons Attribution International License (CC BY 4.0).

http://creativecommons.org/licenses/by/4.0/

\begin{abstract}
Yibin in Sichuan was hailed as the capital of Chinese Liquor. Liquor industry is one of the pillar industries in Yibin. Ten-mile Liquor City, the unique industry tourism garden in the Southern Sichuan, is a remarkable window for propagating Wuliangye liquor culture. However, flaws widely exist in the English version of the public signs, such as lack of translation, grammar mistakes, spelling mistakes, disagreement in translation, semantic fault, wordiness, etc., which not only brought inconvenience for foreign tourists but also damaged both the images of the enterprise and the city. This paper summarized flaws in the translation of public signs from the Wuliangye Ten-mile Liquor City and proposed countermeasures to improve the quality of the translation of public signs.
\end{abstract}

\section{Subject Areas}

Linguistics

\section{Keywords}

Public Signs Translation, Wuliangye, Sichuan Liquor Culture

\section{Introduction}

Public signs refer to all characters and figures used to inform, instruct, compel or warn something that is closely related to our ordinary life and production [1]. Usually, public signs are short and brief, normative, unified, conspicuous [2], with simple structure, plain meaning and proper style [3]. Due to their specific functions (informing, instructing, compelling and warning [4]), public signs act as a carrier of a city's image and have great impact on the tourists' experience. Researches on the public signs boomed after 2003, featured by a hurried start, sharply increasing demand, short history and lacking of precedent [5]. With the 
development and prosperity of tourism industry in China, cites at different scales are striving to explore their knock-out tourism product with marked local features. Meanwhile, most famous scenic areas have provided bilingual or multilingual translations of the public signs to improve their service, facilitate the tour and attract more foreign tourists.

Yibin is located in the south of Sichuan Province, lying to Yunnan and Guizhou to its south, where Jinshajiang, Minjiang and Yangtze River meet. It is considered the richest southwestern city in ancient China and the first city on the Yangtze River. Yibin is both rich in natural tourism resource and human culture resource, and therefore is honored as one of the famous national historic and cultural cities and the favorable tourist cities. As the birthplace of Luzhou-flavor liquor and one of the world famous liquors-Wuliangye, Yibin is hailed as the Capital of Liquor in China. The majestic Wuliangye Ten-Mile City is built due to the rapid development of liquor industry, which is not only filled the gap of enterprise architecture culture but also became the invaluable treasure of the Chinese architecture art. Thousands of admiring tourists from home and abroad were attracted every year. However, flaws still exist in the Chinese-English translation of public signs, which will not only bring inconvenience to foreign tourists but also have negative impact on the images of the scenic area, the enterprise and even the city. Thus, it is an urgent and non-negligible task to remove those flaws in the translation of public signs in order to promote the transmission of Wuliangye's liquor culture.

\section{Principles of the Public Signs Translation}

Translation principles refer to the rules a translator should abide by, and they are regarded a necessary basis to generate qualified translation and meanwhile to restrict over-translation [6]. Chinese scholars have conducted in-depth research on the translation of the public signs, and proposed several principles from different views or based on several theories, which provided guidelines for translators. The following principles have been universally accepted by domestic scholars:

1) Accurate

Being accurate and unified means that there should be no mistakes and flaws in the translation, and the translation should convey all the information provided by original text [7]. Only accurate translation can play its informing, indicating, compelling, warning and servicing functions. Text typology translation theory believes that the primary task of information text is to convey information to recipients [8]. Although the public signs with grammar mistakes or spelling mistakes flaws still can provide basic information to the recipients, they do leave bad impression on the tourists and damage the images and reputation of the scenic spot and the city.

2) Short, brief and straightforward

Being short and brief means to convey more information with less characters, 
in other words, to be economic in words [6], and it is regarded as the fundamental principle due to the restriction of writing room and reading time [9]. Being straightforward means translators need to be frank and avoid being too euphemistic. Public signs in western countries, such as Britain and America usually replace complete sentences with noun, verb, gerund, phrase, characters and figures, abbreviation and imperative sentence [1]. For example, at the scenic spot of Spring of Eternal Peace in Ten-mile Liquor City, a public sign "Tips from Spring of Eternal Peace: Please don't play in the deep water to avoid dropping” is written on a board, most of whose room has been occupied by two lines of Chinese characters. There is such small room left for English translation that the translation has to been written in rather small font, not striking.

3) Popular and easy to understand

Zhang [10] put forward a view that the primary function of text decides the translation principle based on functional translation theory. All the information delivered by public signs should be easy to understand, which requires the translator choose the common and popular words instead of those rarely-used [6] [11] [12].

4) Normative and unified

Being normative means the translation of public signs has to conform to grammar norms and writing habit of the target language. For example, Chinese prefer to use "XX North Road" to show the way, but in western countries, they used to address the road with "North XX Road". The so-called being unified not only means the translation needs to be in line with international conventions but also emphasizes the terms used in the same place should be the same and keep unified in the linguistic stylistic style [8]. The name of place in a scenic area is a term essentially, and as a term, it should be unique and specialized [13]. However, the names of some famous scenic spots at the Ten-mile Liquor City have at least two different translations, which mislead the foreign tourists.

5) Proper mood

$\mathrm{Ni}$ and Liu pointed out that the translator should measure the mood of the source text and find a proper approach to convey the mood in the target text [9]. Public signs can be classified into four categories: prohibitive, caution, imperative and indicative, respectively. "Don't do" or "No doing" can be used to translate the prohibitive text. For cautions, "Danger+" or "Caution+" is suggested. Translators can adopt imperative sentence to translate those imperative signs such as "Keep Clear". Usually, indicative signs are used to show the direction or location of specific objective. Thus, corresponding nouns or phrases can be chose to translate those signs.

6) Intercultural translation

Translation is the bridge connecting two languages or two different cultures [14]. Being common inter-language translation activity, the translation of public signs involves communication and conversion between two cultures. The recipients of the public signs translation are tourists from abroad, so discrepancies 
of culture background, language habits, cultural customs and taboos should be taken seriously when translate the public signs to accommodate special communication environment.

\section{Flaws in the Translation of Public Signs in Ten-Mile Liquor City}

Based on extensive field research, abundant data have been collected from $\mathrm{Wu}$ liangye Ten-mile Liquor City. Errors and flaws do exist in the translation of public signs, including no translation, grammar mistakes, spelling mistakes, disagreement in translation, semantic fault and wordiness.

1) No translation

Wuliangye liquor is fermented with ancient underground cellars with a history of over 600 years. The raw materials of Wuliangye liquor are the five grains of sorghum, rice, sticky rice, wheat and corn. Wuliangye liquor has been distributed in the markets of 65 countries and regions and the brand is performing very successfully in the overseas markets of Chinese liquor. As a treasure of $\mathrm{Si}$ chuan Liquor, Wuliangye undertakes the mission of disseminating Sichuan liquor culture worldwide.

However, in Ten-mile Liquor City, English translation of the public signs related to the fermenting process, enterprise history and development and Chinese liquor drinking habit are not provided at all, except for a small portion of headlines. At the culture museum of Wuliangye Co. Ltd., ancient wine vessels with different styles and shapes, such as bottles with rhinoceros-shaped-handle, elephant-shaped-handle and four sheep-shaped handle, are reflection of Chinese ancient drinking culture, but most foreign tourists probably don't know what they are used to and why they are so different. Lacking of translation brings inconvenience for foreign tourists, and meanwhile contributes nothing for disseminating Sichuan liquor Culture even Chinese liquor culture.

2) Grammar mistake

Grammar mistake is a common mistake in the translation of public signs at the Ten-mile Liquor City. Here are some examples. At the Liquor Saint Mountain, a public sign of "The 225 steps up to top is called the steps to holy mountain" (the sixth picture in Figure 1) demonstrates the disagreement between subject and predicate. At the Sun and Moon Palace, in the sign of "The splendid Sun \& Moon Palace is a modern building build to receive the distinguished guests of Wuliangye CO.", "build" is the root form, but this sentence is a passive one, so its past tense "built" should be used here. At the scenic spot of Spring of Eternal Peace, in the sign of "Spring of eternal peace locates is the Chinese classic landscape architecture of the largest scale in the tourist area" both "locates" and "is" are base forms, so "locates" should be deleted according to the meaning of Chinese source text ( the third picture in Figure 2). Meanwhile, in the sign of "No paddle" (the third picture in Figure 1), "paddle" is a verb, while its present participle should be used here. 

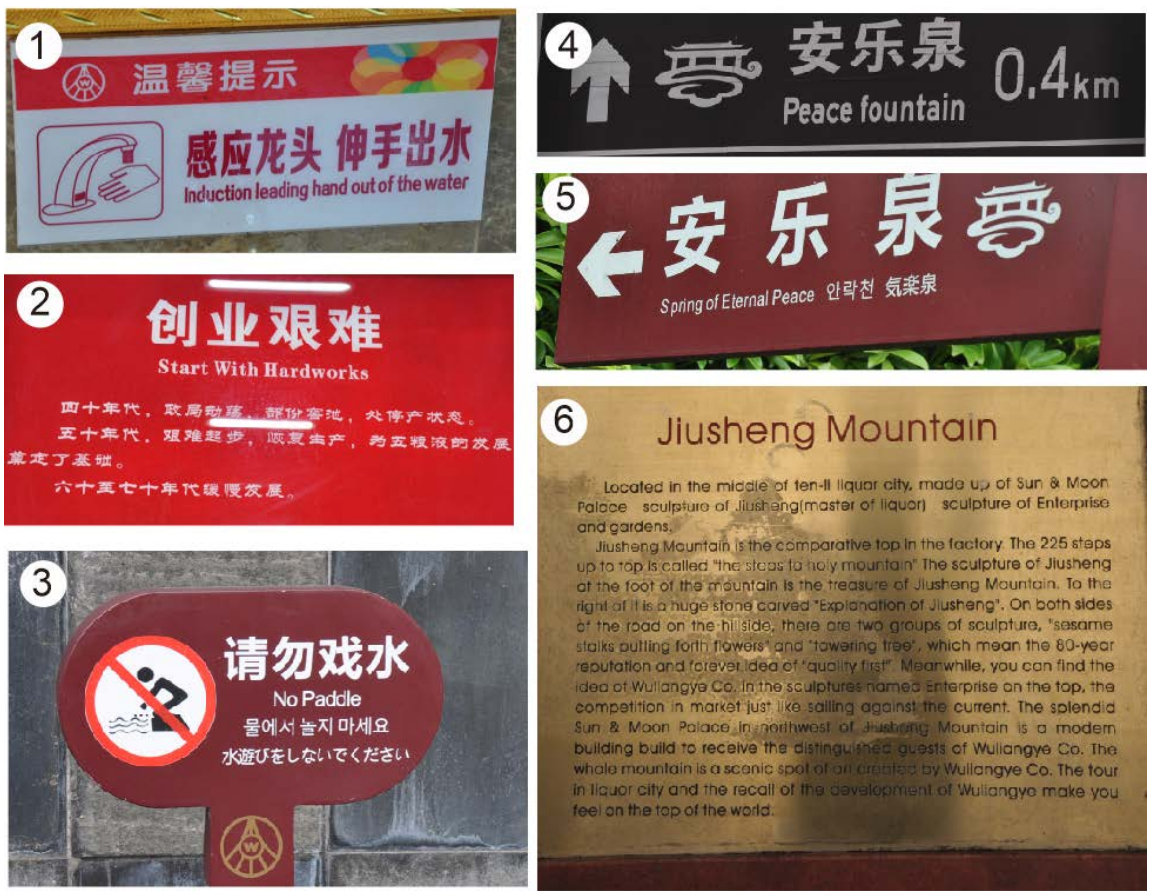

Figure 1. Examples of error or flaws in the English translation of public signs at Wuliangye Ten-mile liquor city.
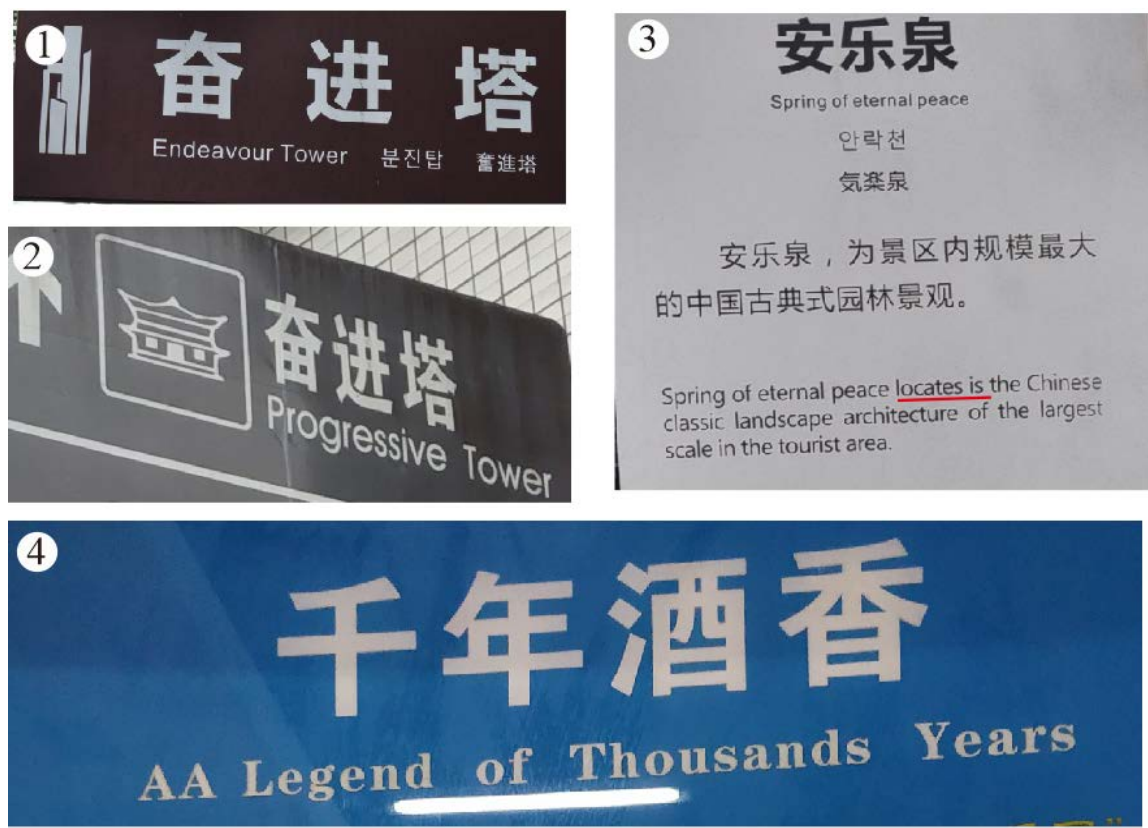

Figure 2. Examples of error or flaws in the English translation of public signs at Wuliangye Ten-mile liquor city.

3) Spelling mistakes

Elementary spelling mistakes left bad image on foreign tourists. For example, at the Wine Culture exhibition center, a sign of "AA legend of thousands years" (the fourth picture in Figure 2) is used to introduce the characteristic of the Wuliangye liquor. Obviously, the two "A" in this sentence repeated. Besides, 
"thousands years" should be replaced by "thousands of years".

\section{4) Disagreement in translation}

At the Ten-mile Liquor City stand a lot of signposts. For Chinese tourists, it is more convenient to tour at the scenic area with those signposts. But on different signposts, the names of the famous scenic spots differ from each other. For example, "Ten mile wine city", "Ten-li liquor city" and "Ten miles liquor city" are used to name the same scenic area. "li" is a Chinese metric unit, but in the name of this scenic area, it is an exaggeration to describe the width of the whole scenic area. To be better conform to the convention of the target language, Chinese "li" should be replaced by English metric unit "mile". Besides, the key difference between wine and liquor is their alcohol content. Wine has lower alcohol content, typically less than $15 \%$ whereas liquor has higher alcohol content, typically over $30 \%$. Wuliangye liquor is the famous Chinese liquor with higher alcohol, thus "Ten-mile liquor city" will be better to name the scenic area. What's more, a mountain at the scenic area has three translations, "Jiusheng Mountain", "Mount Athos Wine" and "Wine Master Mountain", respectively. A spring also has two translations, "Spring of Eternal Peace" and "Peace Fountain" (the fourth and fifth pictures in Figure 1). A tower also has two translations, "Endeavor tower" and "Progressive tower" (the first and second pictures in Figure 1). The same spot is entitled with different names, which no doubt confuses many foreign tourists.

5) Semantic fault

In the bathroom of scenic spot, there is a sign of "The old man is special". The elder in western countries believe "The old is useless", thus the phrase of "The Senior Only" is more acceptable to the foreign tourists. A sign of "Hand out of the water" (the first picture in Figure 1) is pasted next to the sink. In English, the phrase of "hand out" means giving one or more to each person in a group or giving advice or permission to somebody. Actually, this sign is supposed to tell the users how the tap works. So we can use "Automatic Tap" straight. In the introduction of Wuliangye's history, a sign of "The Trans-holder of Chon's Prescription" is used to explain the secret recipe was passed down from Chen to his descendants. In fact, the "trans-holder" has its counterpart in English, which is inheritor, and "Chon" should be "Chen" in Chinese pinyin. In the introduction to the product, the translator applied "Wuliangye First Distinguished" to describe the fact that Wuliangye was first introduced to abroad and got its fame. In fact, there has been its counterpart "Cut a brilliant figure" in English.

6) Wordiness

Wordiness means too much words were used in a translation. A tip from the Spring of Eternal Peace says "Tips from Spring of Eternal Peace: Please don't play in the deep water", which is wordy and can be replaced by the concise "No wading. Deep Water". Besides, all headlines related to the history of Wuliangye company or its products should be translated into "The origin of XXX" to be more economic in words. 


\section{Measures to Improve the Translation of Public Signs}

1) Adopting existing translation

Since Beijing won the Olympic bid, researches on public sign translation have made great achievement. Several provinces have issued provincial standard of English translation of public sign due to endless efforts of several research institute and scholars. Shanghai Language and Character Commission issued the Analysis of Mistakes and Standard of English Translation of Public Sign in 2001. Chinese scholar Cui [15] issued Guidelines of English Translation of Public Sign in 2010. General Administration of Quality Supervision, Inspection and Quarantine of P.R.C. and Standardization Administration of the P.R.C. jointly issued Guidelines for the Use of English in Public Service Areas involving transport, tourism, sport, medical treatment and health care, hotels and restaurants, education, business and mail service. All the aforementioned provide references for the later translators. Thus, translators should consult these references and consider the guidelines priority before conducting translation. It will facilitate improving the translation of public signs and promoting the standardization and normalization of English translation in public service.

2) Abiding by translation principles and adopting translating strategies flexibly

If reference is not provided in all available guidelines, translators can adopt different translating methods and strategies on the basis of abiding by the translation principles, such as transliteration, paraphrase, omission, adaptation, creation, imitating, and adding, etc. For example, there is a special drink habit "Sip liqour" in minorities, such as Miao, Qiang, and Tujia in Sichuan province. "Sip liqour" is not liquor per se, but a drinking habit. In English, there is no its counterpart, so the translator has to explain the drinking process in detail to help foreign tourists understand it. Thus we can use description like "Sip liquor is kind of drinking habit prevalent in several minorities in Sichuan. When entertain the guests, the host will serve them with a bottle of liquor. All the guests need to sip the liquor from the bottle with a bamboo or reed straw then pass it onto the next one. The bottle will be fulfilled with water after a round till the liquor tastes bland. When they finished the liquor, they will eat the lee, which is called 'drink the liquor and have the lees, get drunk and full at the same time”.

3) Improve the translator's ability

$\mathrm{Hu}$ emphasized the ideas of adaption, selection and translator-centered and pointed out the significant role a translator play during translation [16]. The translator's translation level decides the quality of translation and endows the source text a new lease on life. Thus, it is necessary and urgent to enhance the translator's ability to improve the quality of translation. For the translator, he can improve his translation level either by accept relevant training or attending seminars or forums regularly. For the government or relevant research institution, regular training or seminar should be held. Translators who have solid translation foundation can avoid elementary mistake, such as spelling mistake, 
grammar mistake, assumed synonymy and mix-up of parts of speech, etc. Beside solid theoretical knowledge, the translator needs to adopt a cross-cultural awareness to take a full consideration of the expression habit of target language [2]. Since the translation of public signs is assigned responsibility to convey accurate and clear information to the recipients, the translators need to consider and respect foreign tourists' culture, psychology and express habit to facilitate the understanding of translation.

4) Strengthening the cooperation between universities and scenic spots

In academia, the translation of public signs has become a hot topic for a long time. Scholars and relevant administration departments at different levels have made great achievements. Several guidelines and standards of public signs translation have been issued. However, flaws still exist in the translation of public signs at most scenic areas. One of the reasons is that the functional or relevant administration departments of governments and scenic area didn't pay enough attention to the implementation of the guidelines or standards. Quality inspection and evaluation system have not yet been established by the functional department of governments at all levels. For the scenic areas, no fulltime department takes the responsibility for the implementation of the guidelines, and among their employees there is rare talent with high English level, which hinders the process of standardization and normalization of the public signs translation. Most research work is conducting by the universities where qualified talents with high translation level assembly. If the functional department of the government can contribute to cooperation between universities and scenic areas and apply the research achievements in the management of public signs, it will accelerate the process of standardization and normalization of the translation of public signs, improve the images of scenic areas and city, and contribute to the local economy development.

\section{Conclusion}

To some extent, public sign is a business card of a city. Accurate English public signs will facilitate the improvement of city image and reputation and disseminate its unique culture. Wuliangye Yibin Co. Ltd. is an excellent brand of Chinese liquor, famous for its liquor fermentation technology and the local drinking culture. Ten-mile liquor city is a window to disseminate both the culture of Wuliangye Yibin Co. Ltd. and Sichuan liquor. The language environment dominated by public signs has direct and significant impact on the image of the scenic area and the dissemination of liquor culture. However, it is not an overnight thing to solve all the problems existing in the English translation of public signs. Joint efforts from the government, enterprise and research institute are required.

\section{Acknowledgements}

This paper is supported by Research Center for International Transmission of Sichuan Liquor Culture (CJCB2017-03) and Sichuan Provincial Department of 
Education (18SB0492).

\section{References}

[1] Dai, X.Z. and Lv, H.F. (2005) On C-E Translation of Public Signs. Chinese Translators Journal, 26, 38-42.

[2] Ding, H.Q. (2006) Improve Public Signs, Establish References. Chinese Translators Journal, 27, 42-46.

[3] Li, Z.G. (2013) A Survey of Study in Chinese-English Translation of Public Signs Since the Late of 1980s. Journal of Central South University (Social Science), 19, 237-242.

[4] Bei, Z. and Shan, A.M. (2002) Characteristics and C-E Translation of Public Signs. Journal of Beijing International Studies University, 5, 76-79.

[5] Lv, H.F. (2017) Remarks on C-E Sign Translation in the New Normal Context. Shanghai Journal of Translators, 4, 80-87.

[6] Feng, Q. (2015) Quality Evaluation for the Translation of Public Signs. Shanghai Journal of Translators, 2, 18-23.

[7] Wan, H. (2017) Translation of Public Sign: Problems and Countermeasure. Shanghai Journal of Translators, 3, 38-45.

[8] Liu, Y.C. and Wang, H.Y. (2012) Study on the Translation of Public Signs Based on Text Type Theory. Chinese Translators Journal, 33, 89-92.

[9] Ni, C.B. and Liu, Z. (1998) Principles and Examples of the Translation of Public Signs. Shanghai Journal of Translators for Science and Technology, 2, 18-20.

[10] Zhang, M.F. (2006) The Languages of Public Notices in Macao. Shanghai Journal of Translators, 1, 29-34.

[11] Wang, S.H. (2012) Metro Sign Translation: Problems and Principles. Shanghai Journal of Translators, 3, 30-33.

[12] Liu, F.G. and Xu, B.J. (2008) Exploration of Principles of Public Signs Translation. Foreign Language and Their Teaching, 2, 47-50.

[13] Huang, D.X. and Du, X.J. (2007) Guidelines of Public Signs Translation. Terminology Standardization \& Information Technology, 4, 29.

[14] Xu, J.P. and Zhang, R.X. (2002) Foreignization and Domestication: An Examination from the Perspective of Cross-Culture Translation. Chinese Translators Journal, 5, $38-41$.

[15] Cui, X.X. (2010) Guidelines for Chinese-English Translation in Public Places. Zhejiang University Press, Hangzhou, 2.

[16] Hu, G.S. (2011) Eco-Translatology: Research Foci and Theoretical Tenets. Chinese Translators Journal, 32, 5-9. 